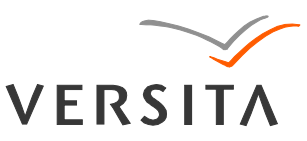

GEOCHRONOMETRIA 38(4) 2011: 369-378

DOI 10.2478/s13386-011-0043-4

Available online at

www.springerlink.com

\title{
ON THE APPLICABILITY OF POST-IR IRSL DATING TO JAPANESE LOESS
}

\author{
CHRISTINE THIEL ${ }^{1,2}$, JAN-PIETER BUYLAERT ${ }^{2,3}$, ANDREW S. MURRAY ${ }^{2}$ and SUMIKO TSUKAMOTO ${ }^{1}$ \\ ${ }^{I}$ Leibniz Institute for Applied Geophysics, S3: Geochronology and Isotope Hydrology, Stilleweg 2, 30655 Hannover, Germany \\ ${ }^{2}$ Nordic Laboratory for Luminescence Dating, Department of Earth Sciences, Aarhus University, \\ Risø DTU, DK 4000 Roskilde, Denmark \\ ${ }^{3}$ Radiation Research Division, National Laboratory for Sustainable Energy, Risø DTU, DK 4000 Roskilde, Denmark
}

Received 15 June 2010

Accepted 19 April 2011

\begin{abstract}
Recent work on infrared stimulated luminescence (IRSL) dating has focussed on finding and testing signals which show less or negligible fading. IRSL signals measured at elevated temperature following IR stimulation at $50^{\circ} \mathrm{C}$ (post-IR IRSL) have been shown to be much more stable than the low temperature IRSL signal and seem to have considerable potential for dating. For Early Pleistocene samples of both European and Chinese loess natural post-IR IRSL signals lying in the saturation region of the laboratory dose response curve have been observed; this suggests that there is no significant fading in nature. As a contribution to the further testing of post-IR IRSL dating, we have used 18 samples from two Japanese loess profiles for which quartz OSL and tephra ages up to $600 \mathrm{ka}$ provide age control. After a preheat of $320^{\circ} \mathrm{C}(60 \mathrm{~s})$, the polymineral fine grains $(4-11 \mu \mathrm{m})$ were bleached with IR at $50^{\circ} \mathrm{C}(200 \mathrm{~s})$ and the IRSL was subsequently measured at $290^{\circ} \mathrm{C}$ for $200 \mathrm{~s}$. In general, the fading uncorrected post-IR IRSL ages agree with both the quartz OSL and the tephra ages. We conclude that the post-IR IRSL signal from these samples does not fade significantly and allows precise and accurate age determinations on these sediments.
\end{abstract}

Keywords: post-IR IRSL dating, fading, Japanese loess.

\section{INTRODUCTION}

Feldspar has considerable potential for extending the age range of luminescence dating because the infrared stimulated luminescence (IRSL) signals from feldspar have a much higher characteristic saturation dose (so called $\mathrm{D}_{0}$ value; $2 * \mathrm{D}_{0} \sim 1-1.5 \mathrm{kGy}$ ), compared to the optically stimulated luminescence (OSL) signal from quartz (where $2 * \mathrm{D}_{0}$ is typically $\sim 0.20 \mathrm{kGy}$ ). However, feldspar suffers from anomalous fading, i.e. a decrease of the IRSL signal with time faster than expected from thermal stability measurements (Wintle, 1973; Spooner, 1994). This usually results in considerable age underestimations.

Corresponding author: C. Thiel

e-mail: christine.thiel@liag-hannover.de
The models proposed to correct for the age underestimation (Lamothe and Auclair, 1999; Huntley and Lamothe, 2001) are strictly only applicable to the linear part of the dose response curve, i.e. to young samples $(<50 \mathrm{ka})$. Lamothe et al. (2003) and Kars et al. (2008) have since proposed approaches which purport to allow for correction beyond the linear part of the dose response curve and thus can in principle be used for older material. However, all corrections models involve un-testable assumptions, including that the fading rate observed on a laboratory timescale is relevant to geological time (e.g. Huntley and Lamothe, 2001; Morthekai et al., 2008).

Recent developments in luminescence dating offer the potential to circumvent the problem of anomalous fading. Thomsen et al. (2008) observed that a post-IR IRSL sig- 
nal (IR stimulation at $50^{\circ} \mathrm{C}$ and subsequent IRSL measurement at $225^{\circ} \mathrm{C}$, blue detection) faded more slowly than conventional IRSL measured at a low stimulation temperature (usually $50^{\circ} \mathrm{C}$, blue detection). The potential of post-IR IRSL dating (preheat of $250^{\circ} \mathrm{C}$ for $60 \mathrm{~s}$ and postIR IR stimulation at $225^{\circ} \mathrm{C}$ for $100 \mathrm{~s}$ ) of sand-sized potassium feldspar has successfully been tested by Buylaert et al. (2009); the fading rate could be reduced by a factor of two compared to the conventional IRSL measurements at $50^{\circ} \mathrm{C}$. Based on the findings of Murray et al. (2009) that the dosimetry trap is not significantly eroded by preheating up to $320^{\circ} \mathrm{C}$, Thiel et al. (2011) adopted a more stringent preheat of $320^{\circ} \mathrm{C}$ for $60 \mathrm{~s}$, which allowed for post-IR IR stimulation at significantly higher temperatures. Because it is advisable to keep the stimulation temperature sufficiently below the preheat temperature to avoid a TL contribution contaminating the optically stimulated signal, Thiel et al. (2011) chose to investigate the use of post-IR IR stimulation at $290^{\circ} \mathrm{C}$. Following the trend observed by Thomsen et al. (2008), it was expected that the measured fading rate is even smaller than for the stimulation temperature tested by Buylaert et al. (2009), because the higher stimulation temperature should allow charge in more distant trap/recombination centres to recombine. Most interestingly, Thiel et al. (2011) found the natural signal of a sample from below the Brunhes/Matuyama (B/M) boundary ( $780 \mathrm{ka}$, expected natural dose $>2700 \mathrm{~Gy}$ ) in saturation on the laboratory regenerated dose response curve, which implies that there is no evidence for anomalous fading in the field using post-IR IR stimulation at $290^{\circ} \mathrm{C}$. Therefore, even though a small fading rate of $\sim 1 \% /$ decade was measured, the fadinguncorrected post-IR IRSL ages were considered to be the most reliable of all the ages presented (Thiel et al., 2011). However, this study was hampered by the quality of the independent age control; only one post-IR IRSL age could be compared with a cluster of radiocarbon ages derived from charcoal.

Whereas independent age control, especially beyond the datable age range of radiocarbon, is lacking in most European loess sequences (e.g. Frechen et al., 1997; Novothny et al., 2002, Thiel et al., 2011), Japanese deposits often include marker tephras for which ages are available (e.g. Machida and Arai, 2003). Watanuki et al. (2005) presented a detailed study on quartz and feldspar luminescence dating of two loess sites in Japan, which could be compared with tephra ages up to $600 \mathrm{ka}$. Using the same set of samples as Watanuki et al. (2005) we test the applicability of the single aliquot regenerative (SAR) dose post-IR IRSL measurement protocol (preheat: $320^{\circ} \mathrm{C}$ for $60 \mathrm{~s}$, post-IR IR stimulation at $290^{\circ} \mathrm{C}$ ) for dating polymineral fine grains $(4-11 \mu \mathrm{m})$ extracted from the loess. All standard laboratory tests such as recuperation, recycling ratios and the ability of this protocol to measure a known dose given in the laboratory are presented and discussed. Laboratory fading rates are also determined and for both sites the derived ages (corrected and uncorrected) are compared with the quartz OSL and tephra ages presented in Watanuki et al. (2005).

\section{SAMPLING LOCATIONS AND INDEPENDENT AGE CONTROL}

In the study of Watanuki et al. (2005) two sequences composed of loessic material intercalated with several tephra were investigated (Fig. 1). A short description of the samples and age control is given below.

At Tsunan-cho in the Niigata Prefecture (Fig. 1a), Central Japan, an up to $9 \mathrm{~m}$ thick sequence covering the oldest terrace (Taniage terrace) was sampled (Watanuki et al., 2005; Fig. 1b). The Aira-Tanzawa (AT) tephra was found at a depth of $0.4 \mathrm{~m}$ below top ground surface (Hayatsu and Arai, 1981). Machida and Arai (2003) presented an age of 26-29 ka for this tephra, based on the correlation of $\delta^{18} \mathrm{O}$ data derived from deep sea cores and the position of AT. Miyairi et al. (2004) presented an uncalibrated high precision radiocarbon age of $25,120 \pm 270 \mathrm{BP}$ for this tephra. One metre further down the section, the Daisen Kurayoshi Pumice (DKP; 55 ka or older; Machida and Arai, 2003) could be identified. The tephra recognised at a depth of $2.8 \mathrm{~m}$ below top ground surface was referred to as the Iizuna-Kamitaru tephra (Iz-KT tephra; 125-150 ka; Suzuki, 2001) because of its position between the Aiyoshi scoria (b) (AY (b); $2.6 \mathrm{~m}$ below surface) and the Honokisaka scoria (HK; $3.3 \mathrm{~m}$ below surface); for the latter two no ages are available. Watanuki et al. (2005) assumed that a tephra of the APm tephra group lies about $9 \mathrm{~m}$ below top ground surface in the section, because this tephra was found by Hayatsu and Arai (1981) at this depth at a location nearby and equivalent to the outcrop of Watanuki et al. (2005). In a later study, the oldest from this tephra group (A1Pm) from the source area was dated to $388 \pm 25 \mathrm{ka}$ using red isothermal thermoluminescence (RITL; Tsukamoto et al., 2007).

From the Niigata section, ten of the twelve samples presented in Watanuki et al. (2005) were used. Information on the samples and intercalated tephras is listed in Table 1.

At Ogawa-machi in the Tochigi Prefecture (Fig. 1a) loessic sediments deposited on the Kitsuregawa Hill and surrounding hill slopes were sampled. Fig. 1c shows a simplified sequence which originates from individual outcrops, i.e. indicated depths are not to be correlated with original sampling depths. The interbedded tephras were dated by means of fission track and radiocarbon dating (Kaizuka et al., 2000; Suzuki et al., 1998; Suzuki, 2001; Machida and Arai, 2003). The Akagi Kanuma Pumice (Ag-KP; 45 ka or older) was identified, followed by the Aso-4 tephra (85-90 ka), the Iizuna-Kamitaru tephra (Iz-KT; 125-150 ka) and the APm-U tephra $(130 \pm 30 \mathrm{ka})$. Furthermore, the Kurodahara tephra (KdP; $200 \pm 30)$ and Nemoto-13, -14 and $-16(\mathrm{Nm}-13,-14,-16$; 330-400 ka) were found (Watanuki et al., 2005); Nm-16 

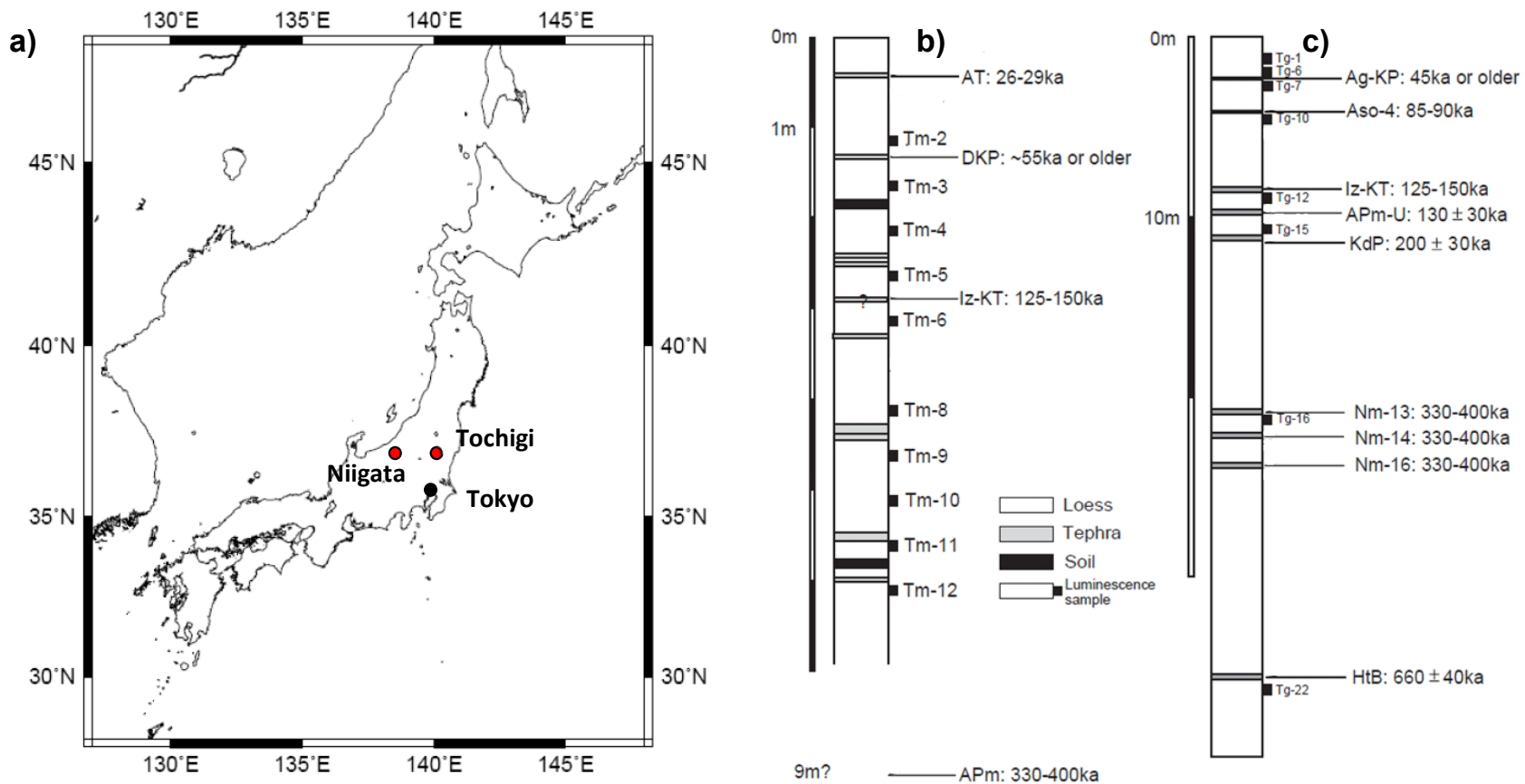

Fig. 1. a) Sampling locations; b) loess section at Tsunan-cho in Niigata Prefecture, Central Japan; c) loess section at Ogawa-machi in Tochigi Prefecture, Eastern Japan. Redrawn from Watanuki et al., 2005.

is equivalent to $\mathrm{A} 1 \mathrm{Pm}$, dated to $388 \pm 25 \mathrm{ka}$ (Tsukamoto et al., 2007). In addition the Hoshitoge Biotite tephra (HtB; $660 \pm 40 \mathrm{ka}$ ) was excavated in the sequence.

From the Tochigi section eight of the twelve samples presented in Watanuki et al. (2005) were used. Information on the samples and intercalated tephras is listed in Table 1.

\section{POST-IR IRSL MEASUREMENTS}

Sample preparation and dosimetry measurements are described in detail in Watanuki et al. (2005). Equivalent dose $\left(D_{e}\right)$ measurements were made with an automated Risø TL/OSL reader (DA-20; Thomsen et al., 2006) using a calibrated ${ }^{90} \mathrm{Sr} /{ }^{90} \mathrm{Y}$ beta source $(\sim 0.21 \mathrm{~Gy} / \mathrm{s})$. The feldspar signal of the polymineral fine grains $(4-11 \mu \mathrm{m})$, mounted on aluminium discs, was stimulated with infrared light diodes emitting at $870 \mathrm{~nm}$, and the luminescence was detected in the blue-violet region through a Schott BG39/Corning 7-59 filter combination. A SAR protocol was used to measure the equivalent dose (one aliquot run at a time). After a preheat of $320^{\circ} \mathrm{C}$ for $60 \mathrm{~s}$ the polymineral fine grains were bleached with IR diodes at $50^{\circ} \mathrm{C}$ for $200 \mathrm{~s}$ and subsequently stimulated with IR diodes for another $200 \mathrm{~s}$ but now with the sample held at $290^{\circ} \mathrm{C}$. It is the latter IRSL signal that is used in the calculations, and we refer to this post-IR IRSL as pIRIR ${ }_{290}$. The response to a test dose was measured in the same manner. An IR illumination at $325^{\circ} \mathrm{C}$ for $100 \mathrm{~s}$ was inserted at the end of each SAR measurement cycle to reduce the effect of recuperation (based on Murray and Wintle, 2003). The initial $1.2 \mathrm{~s}$ of the pIRIR 290 decay curve minus a background from the last $100 \mathrm{~s}$ were used for $\mathrm{D}_{\mathrm{e}}$ determination. The same integration limits were used for the IRSL signal observed during the preceding IR stimulation at $50^{\circ} \mathrm{C}$ (hereafter called $\mathrm{IR}_{50}$ ) for comparison with the pIRIR $_{290}$ data.

The laboratory fading rate, expressed in terms of the percentage decrease of signal intensity per decade of time (the $g$-value; Aitken, 1985) was measured using artificially irradiated aliquots. After $\mathrm{D}_{\mathrm{e}}$ measurement and a final IR illumination at $325^{\circ} \mathrm{C}$ for $100 \mathrm{~s}$, the same aliquots were given a dose of $\sim 180$ Gy and measured using the post-IR IRSL SAR protocol with varying storage times after irradiation and preheat (Auclair et al., 2003). Storage times ranged from as short as experimentally possible ('prompt') to delays of $\sim 10$ hours. Fading rates for both $\mathrm{IR}_{50}$ and pIRIR 290 were calculated following Equation 4 from Huntley and Lamothe (2001) using an excel macro (Huot, private communication, 2008).

To test whether doses given before any heating (i.e. as close as we can get to natural conditions) can be measured accurately, we carried out dose recovery tests. Six natural aliquots of selected samples (Table 1) were bleached for 4 hours in a Hönle SOL2 simulator (sample to lamp distance $\sim 1.2 \mathrm{~m}$ to avoid heating of the aliquots). Three aliquots per sample were then given a beta dose similar to the measured $D_{e}$ for each sample and the given dose measured using the above mentioned settings. Using the other bleached aliquots the equivalent doses after bleaching, i.e. residuals, were measured. 
C. Thiel et al.

Table 1. Sample information, dose rates (taken from Watanuki et al., 2005), recycling ratios, recuperation, measured to given dose ratios, and intercalated tephras for the loess section at Niigata (Tm) and Tochigi Prefecture (Tg).

\begin{tabular}{|c|c|c|c|c|c|c|c|c|c|c|}
\hline \multirow{2}{*}{$\begin{array}{l}\text { Depth } \\
\text { (m) }\end{array}$} & \multirow{2}{*}{ Sample ID } & \multirow{2}{*}{ Tephra name a } & \multirow{2}{*}{$\begin{array}{l}\text { Dose rate } \\
\text { (Gy/ka) a }\end{array}$} & \multirow{2}{*}{$\begin{array}{c}\text { Number of } \\
\text { aliquots }\end{array}$} & \multicolumn{2}{|c|}{ Recuperation (\%) } & \multicolumn{2}{|c|}{ Recycling ratio } & \multicolumn{2}{|c|}{ Measured to given dose ratio } \\
\hline & & & & & $\mathbf{I R}_{50}$ & pIRIR $_{290}$ & $\mathbf{I R}_{50}$ & pIRIR290 & $\mathbf{I R}_{50}$ & pIRIR290 \\
\hline \multicolumn{11}{|c|}{ Niigata } \\
\hline$\overline{0.40}$ & & AT & & & & & & & & \\
\hline 1.10 & $\operatorname{Tm} 2$ & & $1.35 \pm 0.09$ & 6 & $6.3 \pm 1.9$ & $1.9 \pm 0.5$ & $0.88 \pm 0.06$ & $1.00 \pm 0.02$ & $0.85 \pm 0.15$ & $1.01 \pm 0.06$ \\
\hline 1.40 & & DKP & & & & & & & & \\
\hline 1.60 & $\operatorname{Tm} 3$ & & $1.40 \pm 0.10$ & 6 & $5.2 \pm 1.4$ & $1.1 \pm 0.4$ & $1.16 \pm 0.06$ & $0.95 \pm 0.03$ & & \\
\hline 2.10 & $\operatorname{Tm} 4$ & & $1.36 \pm 0.09$ & 6 & $6.2 \pm 1.8$ & $2.4 \pm 0.6$ & $1.08 \pm 0.04$ & $1.00 \pm 0.04$ & & \\
\hline 2.60 & Tm 5 & & $0.95 \pm 0.06$ & 6 & $4.2 \pm 1.2$ & $3.4 \pm 0.6$ & $1.30 \pm 0.30$ & $0.98 \pm 0.03$ & & \\
\hline 2.80 & & Iz-KT & & & & & & & & \\
\hline 3.10 & $\operatorname{Tm} 6$ & & $1.22 \pm 0.10$ & 4 & $4.9 \pm 2.2$ & $1.0 \pm 0.2$ & $1.00 \pm 0.03$ & $1.00 \pm 0.01$ & & \\
\hline 4.10 & $\operatorname{Tm} 8$ & & $1.80 \pm 0.12$ & 4 & $1.3 \pm 0.7$ & $0.8 \pm 0.2$ & $0.99 \pm 0.04$ & $0.99 \pm 0.02$ & $0.91 \pm 0.03$ & $1.57 \pm 0.22$ \\
\hline 4.60 & $\operatorname{Tm} 9$ & & $0.67 \pm 0.06$ & 4 & $4.5 \pm 0.8$ & $1.8 \pm 0.4$ & $0.99 \pm 0.06$ & $1.00 \pm 0.01$ & & \\
\hline 5.10 & $\operatorname{Tm} 10$ & & $0.94 \pm 0.08$ & 4 & $4.7 \pm 1.7$ & $0.9 \pm 0.3$ & $0.97 \pm 0.07$ & $0.98 \pm 0.01$ & & \\
\hline 5.60 & $\operatorname{Tm} 11$ & & $0.86 \pm 0.06$ & 4 & $1.4 \pm 0.1$ & $0.8 \pm 0.2$ & $0.96 \pm 0.04$ & $0.99 \pm 0.01$ & & \\
\hline 6.10 & $\operatorname{Tm} 12$ & & $0.80 \pm 0.06$ & 4 & $2.4 \pm 1.0$ & $1.0 \pm 0.2$ & $0.98 \pm 0.04$ & $0.98 \pm 0.01$ & $1.08 \pm 0.10$ & $1.27 \pm 0.07$ \\
\hline 9.00 & & AlPm & & & & & & & & \\
\hline \multicolumn{11}{|c|}{ Tochigi } \\
\hline$\overline{1.0}$ & $\operatorname{Tg} 1$ & & $1.28 \pm 0.07$ & 4 & $9.1 \pm 4.1$ & $3.8 \pm 2.1$ & $1.04 \pm 0.03$ & $0.99 \pm 0.03$ & $1.40 \pm 0.34$ & $1.03 \pm 0.10$ \\
\hline 1.8 & $\operatorname{Tg} 6$ & & $0.91 \pm 0.05$ & 4 & $7.9 \pm 0.6$ & $4.5 \pm 1.1$ & $1.08 \pm 0.07$ & $1.00 \pm 0.04$ & & \\
\hline 2.0 & $\operatorname{Tg} 7$ & $\mathrm{Ag}-\mathrm{KP}$ & $0.81 \pm 0.04$ & 4 & $4.8 \pm 1.6$ & $4.2 \pm 1.4$ & $1.08 \pm 0.05$ & $0.98 \pm 0.02$ & & \\
\hline 4.1 & $\operatorname{Tg} 10$ & Aso-4 & $0.85 \pm 0.05$ & 4 & $3.5 \pm 1.8$ & $2.7 \pm 0.5$ & $1.11 \pm 0.05$ & $0.96 \pm 0.02$ & & \\
\hline 8.7 & $\operatorname{Tg} 12$ & Iz-KT & $0.72 \pm 0.04$ & 4 & $13.8 \pm 4.4$ & $2.5 \pm 1.1$ & $1.06 \pm 0.07$ & $1.05 \pm 0.05$ & $1.57 \pm 0.45$ & $1.22 \pm 0.09$ \\
\hline 9.6 & & APm-U & & & & & & & & \\
\hline 10.1 & $\operatorname{Tg} 15$ & & $0.94 \pm 0.06$ & 4 & $4.3 \pm 2.1$ & $0.7 \pm 0.1$ & $0.94 \pm 0.04$ & $1.02 \pm 0.05$ & & \\
\hline 11.0 & & KdP & & & & & & & & \\
\hline 20.9 & $\operatorname{Tg} 16$ & $\mathrm{Nm}-13$ & $0.93 \pm 0.05$ & 4 & $6.6 \pm 2.5$ & $0.8 \pm 0.1$ & $1.05 \pm 0.08$ & $1.00 \pm 0.01$ & $0.85 \pm 0.10$ & $1.39 \pm 0.20$ \\
\hline 22.4 & & $\mathrm{Nm}-14$ & & & & & & & & \\
\hline 24.0 & & $\mathrm{Nm}-16$ & & & & & & & & \\
\hline 35.4 & & $\mathrm{HtB}$ & & & & & & & & \\
\hline 35.8 & $\operatorname{Tg} 22$ & & $0.86 \pm 0.07$ & 4 & $6.0 \pm 2.7$ & $0.8 \pm 0.5$ & $1.08 \pm 0.04$ & $1.00 \pm 0.02$ & $1.05 \pm 0.06$ & $1.11 \pm 0.02$ \\
\hline
\end{tabular}

a taken from Watanuki et al., 2005.

\section{MEASUREMENT PERFORMANCE AND FAD- ING}

\section{Niigata}

Laboratory dose response curves of one young (Tm 6) and one old (Tm 12) sample of the Niigata section are shown in Fig. 2. The dose responses of the $\mathrm{IR}_{50}$ and pIRIR $_{290}$ signals are indistinguishable up to $\sim 200 \mathrm{~Gy}$; beyond that the growth curve for pIRIR $_{290}$ signal seems to flatten off earlier. For both samples the natural sensitivity corrected $\mathrm{IR}_{50}$ signal is about $65 \%$ of the sensitivity corrected pIRIR 290 signal; this is representative of all samples from the Niigata section. The initial intensity of the pIRIR $_{290}$ signal is much larger than the rather weak $\mathrm{IR}_{50}$ signal (although the latter is clearly above background; see insets Fig. 2). These observations agree well with former studies on post-IR IRSL dating (Buylaert et al., 2009, Thiel et al., 2011).

Recuperation of the $\mathrm{IR}_{50}$ signal is $<5 \%$ for most samples, ranging from $1.4 \pm 0.1 \%(\mathrm{Tm} 11 ; \mathrm{n}=4)$ to $6.3 \pm 1.9 \%$ $(\mathrm{Tm} 2 ; \mathrm{n}=6)$ (Table 1). For the pIRIR 290 signal recupera- tion varies between $0.8 \pm 0.2 \%(\operatorname{Tm} 8 ; n=4)$ and $3.4 \pm 0.6 \%$ $(\mathrm{Tm} 5 ; \mathrm{n}=6)$. There is no correlation between the recuperation of the $\mathrm{IR}_{50}$ signal and that of the pIRIR ${ }_{290}$ signal. Watanuki et al. (2005) observed similar recuperation when using IRSL at $50^{\circ} \mathrm{C}$ (detection in the UV), but found recuperation $>10 \%$ in many of the quartz OSL measurements. Recycling ratios for both signals and all samples are within $10 \%$ of unity. The results of dose recovery tests, which were conducted for three samples of the Niigata section (Table 1), varied considerably among different samples (Fig. 3). The mean measured to given ratios after subtraction of a residual signal ( IRIR $_{290} 20 \pm 2$ Gy $(\mathrm{n}=9), \mathrm{IR}_{50} 5 \pm 1$ Gy $\left.(\mathrm{n}=9)\right)$ are $1.28 \pm 0.12(\mathrm{n}=9)$ for $\mathrm{pIRIR}_{290}$ and $0.95 \pm 0.09(\mathrm{n}=9)$ for $\mathrm{IR}_{50}$, respectively. We speculate that the large residuals and the not very satisfactory dose recovery results might suggest that the bleaching in the SOL2 simulator is not representative of bleaching in nature. The measured fading rates for pIRIR $_{290}$ vary between $0.04 \pm 1.17 \% /$ decade $(\mathrm{n}=3)$ and $1.94 \pm 1.43 \% /$ decade $(\mathrm{n}=3)$; negative $g$-values were derived for $\mathrm{IR}_{50}$ (Table 2) which may indicate some form of recuperation with storage. We do not have an explanation 
for this increase of the $\mathrm{IR}_{50}$ signal intensity with time. This clearly needs further investigations but lies out of the scope of this dating study (which is focused on the applicability of the pIRIR 290 signal).

\section{Tochigi}

Most samples from the Tochigi section show characteristics (Fig. 4) and SAR performance (Table 1) similar to Niigata section. The dose response curves of $\mathrm{IR}_{50}$ and pIRIR $_{290}$ for sample Tg 6 (representative of samples Tg 1 to $\mathrm{Tg}$ 10) are identical up to $300 \mathrm{~Gy}$ (Fig. 4a), whereas for sample $\mathrm{Tg} 22$, representing samples $\mathrm{Tg} 12$ to $\mathrm{Tg} 22$, the curves are indistinguishable up to $\sim 150$ Gy with a steeper growth for the $\mathrm{IR}_{50}$ at larger doses (Fig. 4b). For the young samples ( $\operatorname{Tg} 1$ to $\operatorname{Tg} 6$ ) the sensitivity corrected natural pIRIR 290 is smaller than that of $\operatorname{IR}_{50}$ (Fig. 4a; see also equivalent doses in Table 2), whereas for the older samples the opposite is true; this difference is very pronounced for the oldest sample (Tg 22; Fig. 4b).

For the $\mathrm{IR}_{50}$ signal recuperation for only three samples is $<5 \%(\operatorname{Tg} 7, \operatorname{Tg} 10$ and $\operatorname{Tg} 15$; Table 1$)$; the values vary
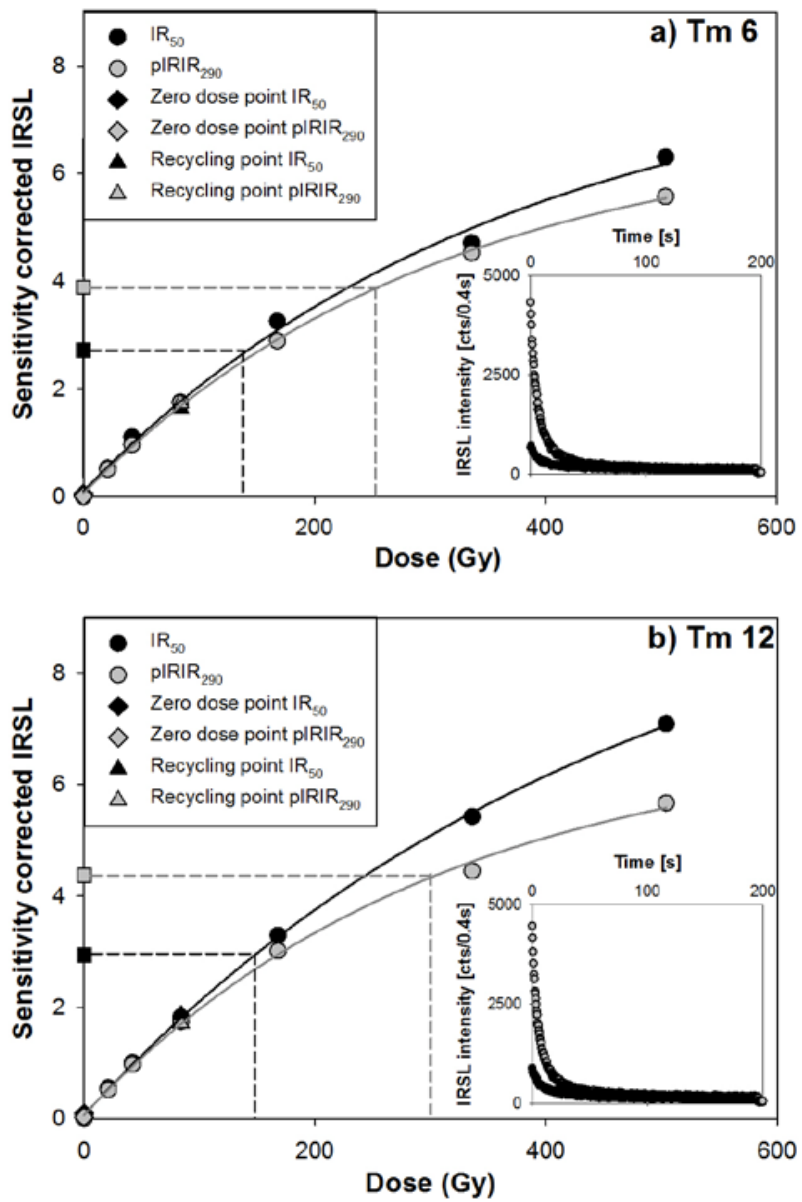

Fig. 2. Dose response and natural decay curves (inset) for samples $\mathrm{Tm} 6$ (a) and Tm 12 (b); the latter represents the oldest sample at the section in Niigata Prefecture.

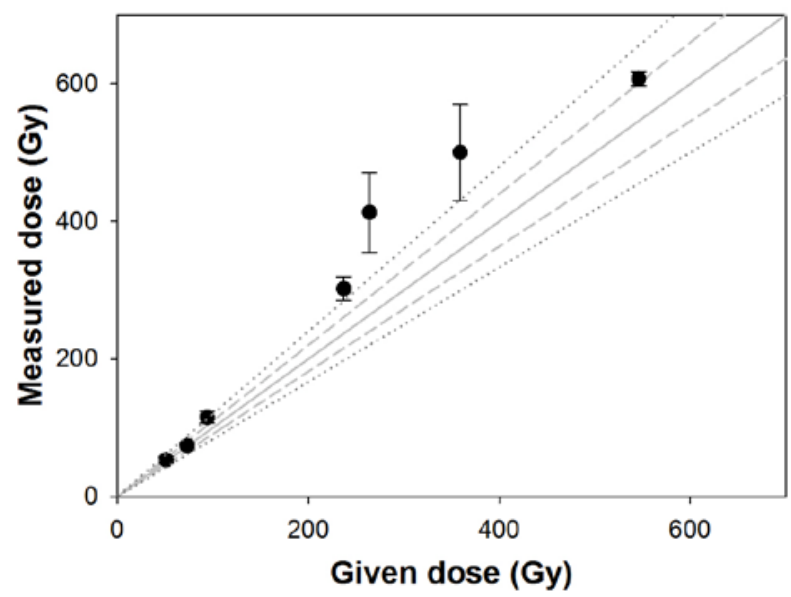

Fig. 3. Measured doses plotted against given doses of pIRIR 290 for all samples from Niigata and Tochigi. The errors shown are 10. Dose recovery results for $I R 50$ are not shown, because the focus of this study is the pIRIR290 signal. For completeness, the dose recovery results of $I_{50}$ are presented in section 4 . The dashed lines indicate $\pm 10 \%$ around unity and the dotted lines $\pm 20 \%$, respectively.
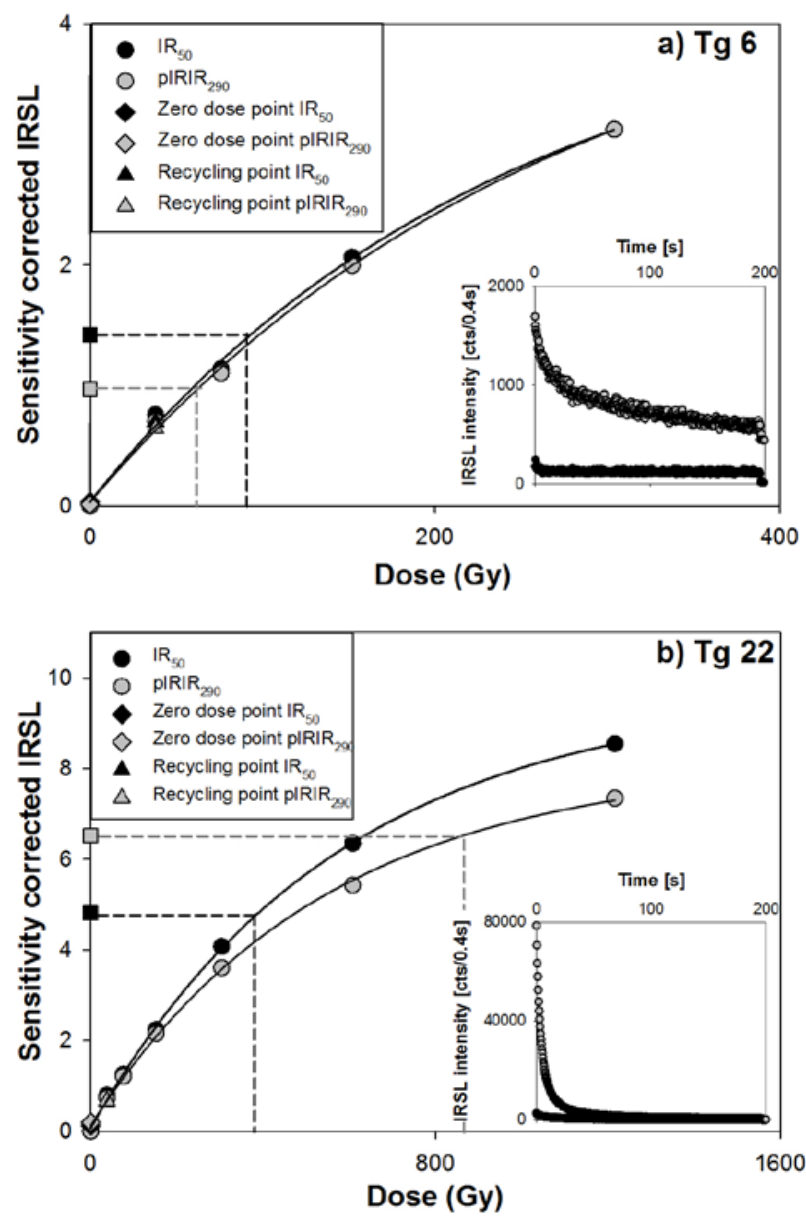

Fig. 4. Dose response and natural decay curves (inset) for samples $\operatorname{Tg} 6$ (a) and $\operatorname{Tg} 22$ (b); the latter represents the oldest sample at the section in Tochigi Prefecture. 
between $3.5 \pm 1.8 \%(\mathrm{Tg} 10 ; \mathrm{n}=4)$ and $13.8 \pm 4.4 \%(\mathrm{Tg} 12$; $\mathrm{n}=4$ ) and are significantly larger than for Niigata section. Recuperation for the pIRIR 290 signal is smaller and ranges from $0.7 \pm 0.1 \%(\operatorname{Tg~} 15 ; n=4)$ to $4.5 \pm 1.1 \%(\operatorname{Tg~} 6 ; n=4)$. The dose recovery test results are similar to the Niigata section (Table 1; Fig. 3). After subtraction of a residual (pIRIR $29015 \pm 2$ Gy, IR $_{50} 3 \pm 1 \mathrm{~Gy}$ ) the mean measured to given dose ratios are $1.19 \pm 0.10(\mathrm{n}=9)$ for $\mathrm{pIRIR}_{290}$ and $1.22 \pm 0.24(\mathrm{n}=9)$ for $\mathrm{IR}_{50}$.

The laboratory fading rates range from $0.07 \pm 0.78$ $\% /$ decade $(n=3)$ to $2.00 \pm 0.64 \% /$ decade $(n=3)$. For $I_{50}$ negative values were again observed (Table 2). Watanuki et al. (2005) also found an IRSL signal increase (measured in the UV) of $\sim 280 \%$ for the sample which they measured after storage at $100^{\circ} \mathrm{C}$ for two weeks; this is hence in accordance with our observations.

\section{Does the pIRIR $_{290}$ signal show significant fading?}

The distributions of the fading rates for both IRSL signals from both sites are shown in Fig. 5. The measured negative fading rates for $\mathrm{IR}_{50}$ (in the following referred to as 'apparent fading rate'; Table 2) are presumably not representative of what is occurring in nature. The measured fading rates for pIRIR 290 are on average close to 1.0 (Fig. 5b), but due to the unreliability of the $\mathrm{IR}_{50}$ fading rates it is difficult to judge whether the measured fading rates for $\mathrm{pIRIR}_{290}$ represent the natural fading rates. This emphasises the need for IRSL dating procedures that are
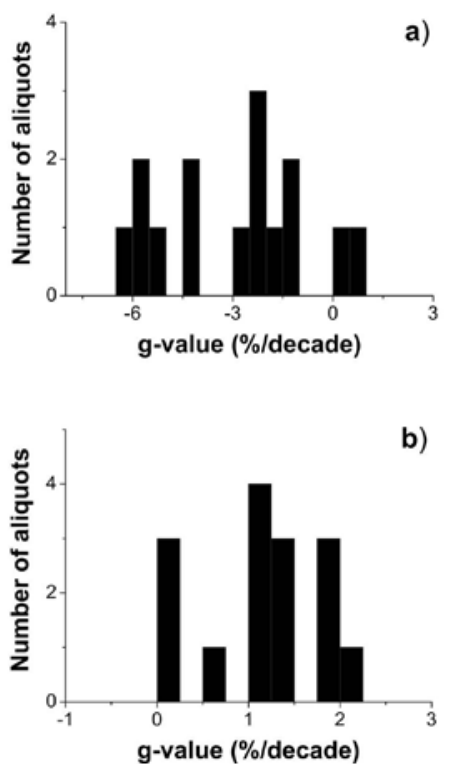

Fig. 5. Histograms of g-values measured for a) $I R_{50}$ and b) pIRIR $R_{290 \text {, }}$ showing that for pIRIR290 the g-values scatter around $1.0 \% / d e c a d e$. not reliant on fading corrections. It has been suggested that the post-IR IRSL signal measured at $290^{\circ} \mathrm{C}$ does not fade significantly (Thiel et al. 2011), based on the observation of a natural signal in saturation on a laboratory dose response curve for a sample from below $\mathrm{B} / \mathrm{M}$ boundary. The observations of Thiel et al. (2011) were made on polymineral fine grains extracted from European loess; the luminescence characteristics and fading behaviour are however not identical to the sites under study. There is no Japanese loess old enough to be in saturation. We refer to the work of Buylaert et al. (2011) in which they investigated the saturation behaviour of the pIRIR $_{290}$ signal from a Chinese loess sample (Luochuan section) from well below B/M boundary. If indeed Japanese loess is a mixture of Chinese loess, air-fall tephra and local dust (Suzuki, 1995) then this sample should be at least partly representative of our material

Fig. 6 shows the dose response curve for the polymineral fine grain extracts from China with the naturals of the $\mathrm{IR}_{50}$ signal and the pIRIR ${ }_{290}$ signal interpolated on the curves. The $L_{x} / T_{x}$ values were normalised using the saturation value. It is evident that the natural for the pIRIR $_{290}$ signal is in, or close to saturation, whereas the natural for the $\mathrm{IR}_{50}$ signal is less than $60 \%$ of the laboratory saturation level. From that we conclude that it is unlikely that any fading correction is needed when making use of pIRIR 290 ; the following discussion thus concentrates on the uncorrected pIRIR ${ }_{290}$ signal, and all ages are presented without the subtraction of a residual.

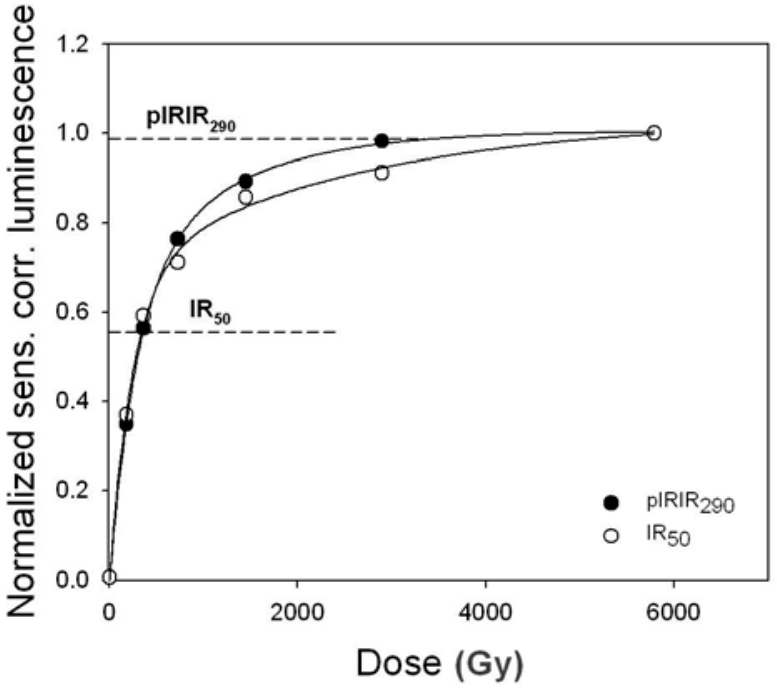

Fig. 6. Dose response curves for a Chinese loess sample from well below Brunhes/Matuyama boundary. The expected dose is $\sim 3 k G y$. The dashed lines show the natural of $I R_{50}$ and pIRIR290, respectively. (modified from Buylaert et al., 2011) 


\section{COMPARISON WITH INDEPENDENT AGE CONTROL}

\section{Niigata section}

At the Niigata section the uncorrected pIRIR $_{290}$ ages, apart from two outliers (Tm 8 and Tm 10; Table 2), increase with depth (Fig. 7) and follow the trend of the tephra ages. For comparison, the fading uncorrected $\mathrm{IR}_{50}$ ages are also plotted in Fig. 7; these clearly show field saturation at $\sim 150 \mathrm{ka}$ (in this context, field saturation is the condition where the rate of charge trapping is equal to the rate of charge loss). It should be remembered that fading correction of the $\mathrm{IR}_{50}$ ages would not improve this comparison because: (i) the apparent fading rates are negative; (ii) once in field saturation any chronological information is lost; and (iii) there are no proven fading correction methods that can be applied beyond the linear region of the growth curve. The two outliers in pIRIR 290 age follow the trend of the quartz ages, in that the ages are younger than those of the overlying samples (Table 2 ); this suggests a problem with the dose rate estimation rather than a dose measurement problem because the measured water content for these samples were over $100 \%$. Overall there is good agreement with the quartz ages presented in Watanuki et al. (2005). This can be seen in Fig. 8, where the pIRIR 290 ages are plotted against the quartz OSL ages (a comparison with tephra ages is not shown here because they do not originate from the same depths). The pIRIR 290 tend to overestimate the quartz ages for the younger sample by $5-10 \%$; this overestimate rapidly decreases for the older samples, and is negligible $>150$ ka. Sample Tm 12 (pIRIR $290: 291 \pm 33 \mathrm{ka})$

Table 2. Equivalent doses, g-values, fading uncorrected and fading corrected ages for Niigata (Tm) and Tochigi (Tg). For comparison quartz OSL and tephra ages taken from Watanuki et al. (2005) are listed.

\begin{tabular}{|c|c|c|c|c|c|c|c|c|c|c|c|}
\hline \multirow[t]{2}{*}{$\begin{array}{l}\text { Depth } \\
\text { (m) }\end{array}$} & \multirow[t]{2}{*}{ Sample ID } & \multicolumn{2}{|c|}{$\begin{array}{l}\text { Equivalent dose } \\
\text { (Gy) }\end{array}$} & \multicolumn{2}{|c|}{$\begin{array}{c}g \text {-value } \\
\text { (\%/decade) }\end{array}$} & \multicolumn{2}{|c|}{$\begin{array}{l}\text { fading uncorrected } \\
\text { age (ka) }\end{array}$} & \multicolumn{2}{|c|}{$\begin{array}{l}\text { fading corrected } \\
\text { age (ka) }\end{array}$} & \multirow[t]{2}{*}{$\begin{array}{c}\text { Tephra } \\
\text { age (ka) }{ }^{c}\end{array}$} & \multirow[t]{2}{*}{$\begin{array}{l}\text { Quartz OSL } \\
\text { age (ka) d }\end{array}$} \\
\hline & & $\mathbf{I R}_{50}$ & pIRIR 290 & $\mathrm{IR}_{50}$ & pIRIR 290 & $\mathbf{I R}_{50}$ & pIRIR 290 & $\mathbf{I R}_{50}$ & pIRIR & & \\
\hline \multicolumn{12}{|c|}{ Niigata } \\
\hline$\overline{0.40}$ & & & & & & & & & & $26-29$ & \\
\hline 1.10 & $\mathrm{Tm} 2$ & $48 \pm 5$ & $86 \pm 3$ & $-4.50 \pm 1.19$ & $1.11 \pm 1.00$ & $35 \pm 4$ & $64 \pm 2$ & n.a. ${ }^{a}$ & $70 \pm 9$ & & $56 \pm 4$ \\
\hline 1.40 & & & & & & & & & & $\geq 55$ & \\
\hline 1.60 & $\mathrm{Tm} 3$ & $99 \pm 5$ & $143 \pm 7$ & $-2.04 \pm 1.26$ & $1.04 \pm 0.89$ & $71 \pm 4$ & $102 \pm 5$ & n.a. ${ }^{a}$ & $112 \pm 14$ & & $81 \pm 6$ \\
\hline 2.10 & $\mathrm{Tm} 4$ & $95 \pm 12$ & $160 \pm 4$ & $-2.31 \pm 1.27$ & $1.41 \pm 1.07$ & $70 \pm 9$ & $118 \pm 3$ & n.a. ${ }^{a}$ & $134 \pm 17$ & & $99 \pm 7$ \\
\hline 2.60 & $\operatorname{Tm} 5$ & $112 \pm 17$ & $161 \pm 9$ & n.a. & n.a. & $118 \pm 18$ & $170 \pm 10$ & n.a. & n.a. & & $145 \pm 14$ \\
\hline 2.80 & & & & & & & & & & $125-150$ & \\
\hline 3.10 & $\operatorname{Tm} 6$ & $157 \pm 25$ & $284 \pm 30$ & $-1.22 \pm 1.25$ & $1.82 \pm 1.09$ & $128 \pm 22$ & $233 \pm 26$ & n.a. ${ }^{a}$ & $276 \pm 49$ & & $155 \pm 19 \mathrm{e}$ \\
\hline 4.10 & $\operatorname{Tm} 8$ & $155 \pm 15$ & $298 \pm 27$ & $0.32 \pm 1.73$ & $1.76 \pm 1.13$ & $86 \pm 9$ & $166 \pm 16$ & $89 \pm 14^{b}$ & $195 \pm 32$ & & $156 \pm 12$ \\
\hline 4.60 & $\operatorname{Tm} 9$ & $93 \pm 5$ & $175 \pm 8$ & $-1.81 \pm 2.31$ & $0.12 \pm 1.34$ & $138 \pm 9$ & $261 \pm 14$ & n.a. ${ }^{a}$ & $264 \pm 33$ & & $203 \pm 21^{\mathrm{e}}$ \\
\hline 5.10 & $\operatorname{Tm} 10$ & $115 \pm 4$ & $205 \pm 13$ & n.a. & n.a. & $122 \pm 5$ & $218 \pm 16$ & n.a. & n.a. & & $199 \pm 18$ \\
\hline 5.60 & $\operatorname{Tm} 11$ & $124 \pm 8$ & $270 \pm 23$ & $-4.39 \pm 2.01$ & $0.04 \pm 1.17$ & $144 \pm 10$ & $314 \pm 28$ & n.a. ${ }^{a}$ & $315 \pm 39$ & & $298 \pm 23$ \\
\hline 6.10 & $\operatorname{Tm} 12$ & $111 \pm 12$ & $233 \pm 25$ & $0.91 \pm 2.01$ & $1.94 \pm 1.43$ & $139 \pm 16$ & $291 \pm 33$ & $151 \pm 31^{b}$ & $351 \pm 72$ & & $228 \pm 20$ \\
\hline 9.00 & & & & & & & & & & $330-400$ & \\
\hline \multicolumn{12}{|c|}{ Tochigi } \\
\hline$\overline{1.0}$ & $\operatorname{Tg} 1$ & $109 \pm 25$ & $67 \pm 3$ & & & $85 \pm 9$ & $52 \pm 7$ & & & & $36 \pm 3^{e}$ \\
\hline 1.8 & $\operatorname{Tg} 6$ & $88 \pm 7$ & $59 \pm 7$ & $-6.03 \pm 1.38$ & $1.02 \pm 0.91$ & $97 \pm 6$ & $65 \pm 5$ & n.a. ${ }^{a}$ & $71 \pm 11$ & & \\
\hline 2.0 & $\operatorname{Tg} 7$ & $72 \pm 10$ & $53 \pm 4$ & $-5.07 \pm 1.73$ & $0.07 \pm 0.78$ & $89 \pm 6$ & $65 \pm 4$ & n.a. ${ }^{a}$ & $59 \pm 6$ & $\geq 45$ & \\
\hline 4.1 & $\operatorname{Tg} 10$ & $68 \pm 11$ & $118 \pm 14$ & $-5.96 \pm 1.71$ & $1.09 \pm 0.16$ & $80 \pm 14$ & $139 \pm 18$ & n.a. ${ }^{a}$ & $154 \pm 18$ & $85-90$ & $94 \pm 10$ \\
\hline 8.7 & $\operatorname{Tg} 12$ & $40 \pm 6$ & $101 \pm 2$ & $-5.52 \pm 2.24$ & $2.00 \pm 0.64$ & $56 \pm 4$ & $141 \pm 8$ & n.a. ${ }^{a}$ & $170 \pm 16$ & $125-150$ & \\
\hline 9.6 & & & & & & & & & & $130 \pm 30$ & $150 \pm 15$ \\
\hline 10.1 & $\operatorname{Tg} 15$ & $90 \pm 3$ & $227 \pm 25$ & $-2.34 \pm 1.63$ & $1.47 \pm 0.24$ & $95 \pm 6$ & $241 \pm 18$ & n.a. ${ }^{a}$ & $277 \pm 36$ & & $209 \pm 14$ \\
\hline 11.0 & & & & & & & & & & $200 \pm 30$ & \\
\hline 20.9 & $\operatorname{Tg} 16$ & $97 \pm 30$ & $384 \pm 87$ & $-1.47 \pm 1.73$ & $1.45 \pm 0.31$ & $104 \pm 16$ & $413 \pm 43$ & n.a. ${ }^{a}$ & $474 \pm 111$ & $330-400$ & $303 \pm 20$ \\
\hline 22.4 & & & & & & & & & & $330-400$ & \\
\hline 24.0 & & & & & & & & & & $330-400$ & \\
\hline 35.4 & & & & & & & & & & $660 \pm 40$ & \\
\hline 35.8 & $\operatorname{Tg} 22$ & $204 \pm 52$ & $528 \pm 33$ & $-2.91 \pm 1.81$ & $0.74 \pm 0.15$ & $237 \pm 35$ & $614 \pm 52$ & n.a. ${ }^{a}$ & $658 \pm 68$ & & $507 \pm 41$ \\
\hline
\end{tabular}

a Fading correction could not be applied due to negative g-values.

${ }^{b}$ Fading correction is using the measured g-value, which is assumed to be not representative for what is occurring in nature. For details see text.

c Tephra ages taken from Wanatuki et al., 2005. For more details on the tephra ages see text.

${ }^{d}$ Quartz OSL ages taken from Watanuki et al., 2005. Unless otherwise indicated the OSL ages are Component-1 quartz blue-OSL, which has been considered the most reliable age estimate.

e Component-1 polymineral blue-OSL age; no Component-1 quartz blue-OSL age available. 
seems to overestimate the relevant quartz OSL age ( $228 \pm 20 \mathrm{ka})$, but compared to the pIRIR 290 and OSL ages of the overlying sample (Tm 11), it is more likely that the quartz OSL age of Tm 12 is an underestimate (Table 2).

\section{Tochigi section}

The observations for Tochigi section are similar to the Niigata section. The uncorrected pIRIR 290 ages are plotted against depth in Fig. 9; for comparison the fading uncorrected $\mathrm{IR}_{50}$ ages are shown. The uppermost samples show surprising behaviour, with fading uncorrected $\mathrm{IR}_{50}$ ages older than pIRIR 290 ages (Table 2). As at Niigata, a

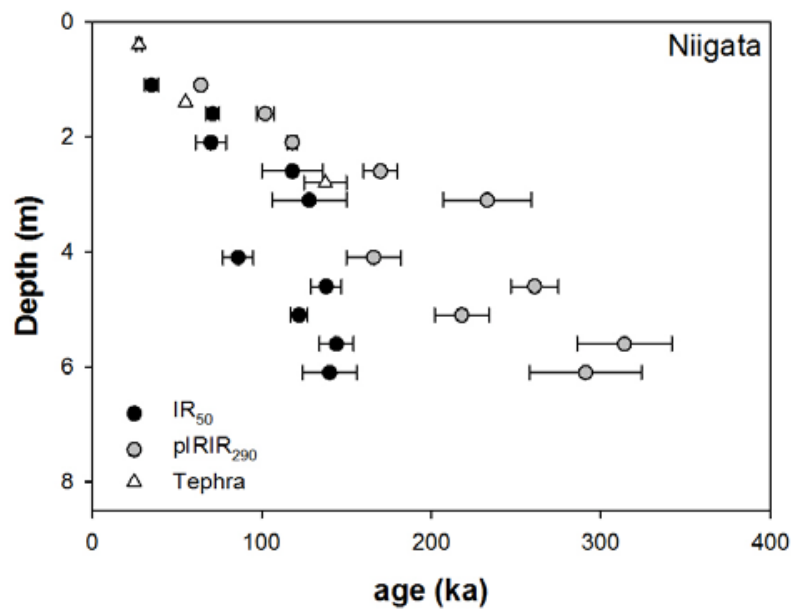

Fig. 7. Fading uncorrected $I R_{50}$ ages (black circles), uncorrected pIRIR 290 ages (grey circles) and tephra ages (open triangles) of Niigata plotted against depth. The IR $R_{50}$ ages saturate at about $150 \mathrm{ka}$, whereas the pIRIR 290 ages increase with depth (apart from two outliers; for details see text). The errors are given as $1 \sigma$.

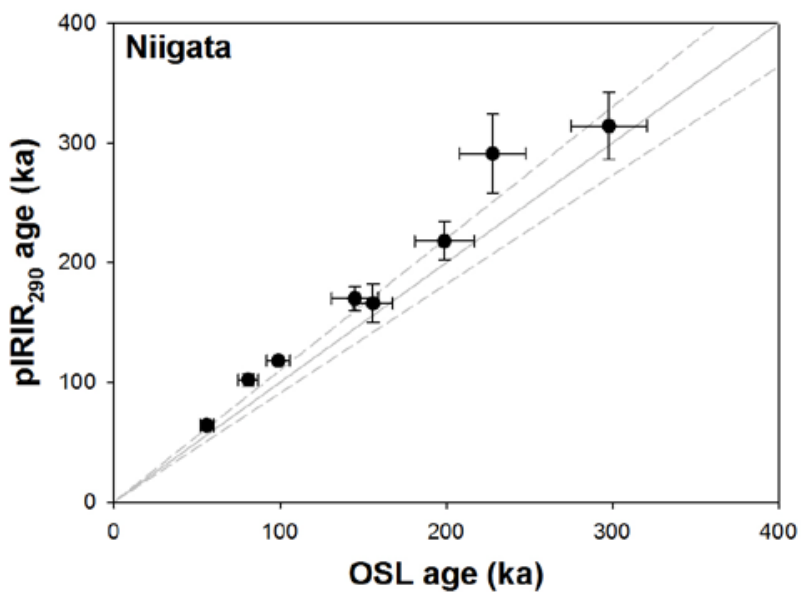

Fig. 8. Fading uncorrected pIRIR 290 ages plotted against OSL ages (taken from Watanuki et al., 2005). The errors shown are $1 \sigma$. Compared to the OSL ages, the pIRIR 290 ages tend to overestimate up to $10 \%$ (dashed lines show $\pm 10 \%$ around unity). small overestimation of the tephra age for the younger samples is seen, but the pIRIR 290 ages clearly result in more reliable age estimates than the $\mathrm{IR}_{50}$ signal; for the older samples $(>200 \mathrm{ka})$ there is good agreement with the tephra ages. This is also shown in Fig. 10, which also includes a comparison with quartz OSL ages. Apart from sample Tg 10, for which the pIRIR 290 age is an overestimate of $\sim 25 \mathrm{ka}$ compared to the tephra and quartz OSL ages (Table 2), there is a good agreement of IRIR $_{290}$ and tephra ages. Compared to quartz OSL, the pIRIR 290 results seem to overestimate for the older samples (Fig. 10; Table 2); however, Watanuki et al. (2005) found that for

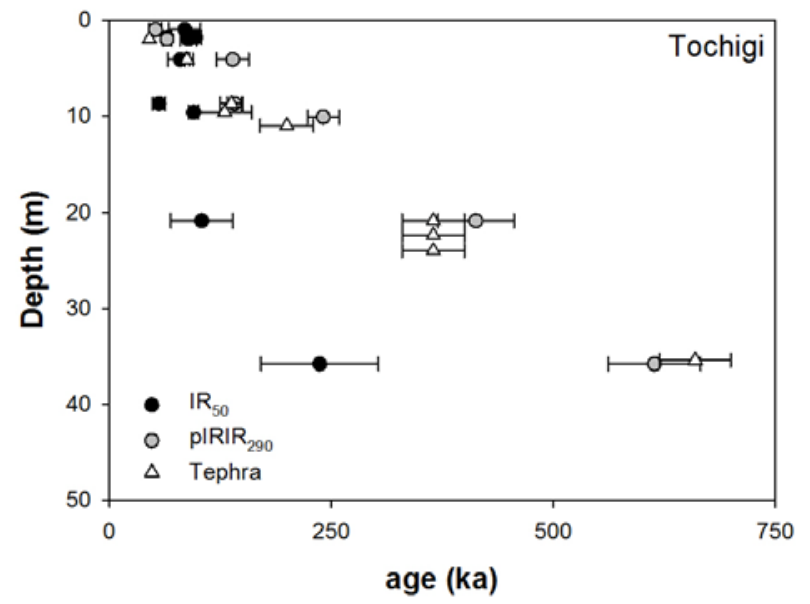

Fig. 9. Fading uncorrected $I R_{50}$ ages (black circles), uncorrected pIRIR 290 ages (grey circles) and tephra ages (open triangles) of Tochigi plotted against depth. The pIRIR290 ages show a clear increase with depth. The errors are given as $1 \sigma$.

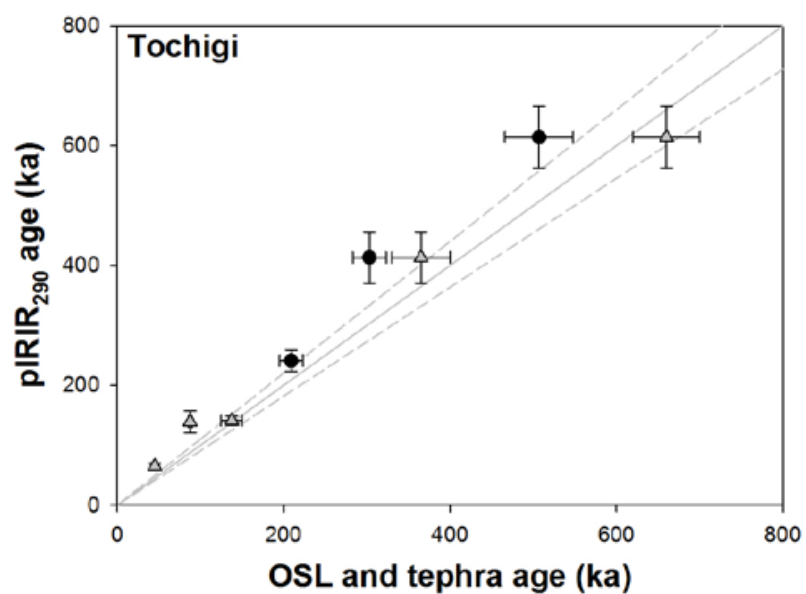

Fig. 10. Uncorrected pIRIR $R_{290}$ ages plotted against OSL ages (black circles) and tephra ages (grey triangles), respectively (OSL and tephra ages taken from Watanuki et al., 2005). The pIRIR290 ages are within errors $(1 \sigma)$ in reasonable agreement with the tephra ages for most of the samples, whereas they tend to overestimate the OSL ages (dashed lines show $\pm 10 \%$ around unity). For discussion see text. 
the older samples the quartz OSL ages tend to slightly underestimate the tephra ages. We conclude that the pIRIR $_{290}$ ages can be considered at least as reliable as the quartz OSL ages.

At both sites there is a tendency for the pIRIR 290 to slightly overestimate the quartz ages (Table 2; Figs. 8 and 10). For the younger ages this is likely to arise from the residual doses observed (but not subtracted, cf. Thiel et al., 2011). For older material, the residual is not significant; in this age range we consider it more likely that the quartz ages underestimate the true ages. Watanuki et al. (2005) concluded that the quartz $\mathrm{D}_{\mathrm{e}}$ values are likely to be saturated although the dose response curve still grows, and so the pIRIR 290 ages are more likely to be correct. This conclusion is supported by the good agreement between the pIRIR ${ }_{290}$ and tephra ages for the lowest level at the Tochigi site.

\section{CONCLUSIONS}

We have tested an elevated temperature post-IR IRSL dating protocol on two Japanese loess sections for which quartz OSL and tephra ages are also available. The elevated temperature post-IR IRSL signal was measured at $290^{\circ} \mathrm{C}$ after a preheat of $320^{\circ} \mathrm{C}(60 \mathrm{~s})$ and an IR bleach at $50^{\circ} \mathrm{C}$. The applicability of our SAR protocol was tested by examining the standard criteria, i.e. recycling ratios, recuperation, and measured to given dose ratios in dose recovery experiments. Recuperation of the pIRIR 290 signal is $<5 \%$ for all samples and all recycling ratios are close to unity. Dose recovery results are less satisfactory, and are both around two standard errors greater than unity. Nevertheless, it is evident from the comparison with the independent age control that our SAR post-IR IRSL dating results in ages that are at least as accurate as quartz, and possibly more so. These data are not corrected for fading, and this decision is supported by the natural pIRIR $_{290}$ signal lying in the saturated region of the laboratory growth curve in a loess sample from an upwind Chinese site.

We present this study as a step towards more reliable feldspar luminescence dating. Our data show that post-IR IRSL dating is applicable to polymineral fine grains extracted from Japanese loess. Future work needs to focus on a better understanding of the physical processes involved in post-IR IRSL dating, an explanation of the unsatisfactory dose recovery experiments, and more appropriate measurements protocols applicable to different environments.

\section{ACKNOWLEDGEMENTS}

This paper is dedicated to the memory of Takuya Watanuki. CT and ST have been supported by the Leibniz Pakt for Research and Innovation 2008-10. We are grateful to Mayank Jain and Kristina Thomsen for fruitful discussions on post-IR IRSL dating. We appreciate the reviewers' comments on an earlier version of this manuscript.

\section{REFERENCES}

Aitken MJ, 1985. Thermoluminescence Dating. London, Academic Press: 359pp.

Auclair M, Lamothe M and Hout S, 2003. Measurement of anomalous fading for feldspar IRSL using SAR. Radiation Measurement 37(4-5): 487-492, DOI 10.1016/S1350-4487(03)00018-0.

Buylaert JP, Murray AS, Thomsen KJ and Jain M, 2009. Testing the potential of an elevated temperature IRSL signal from K-feldspar. Radiation Measurements 44(5-6): 560-565, DOI 10.1016/j.radmeas.2009.02.007.

Buylaert JP, Thiel C, Murray AS, Vandenberghe DAG, Yi S, Lu H, 2011. IRSL and post-IR IRSL residual doses recorded in modern dust samples from the Chinese Loess Plateau. Geochronometria 38(4): 432-440, DOI 10.2478/s13386-011-0047-0.

Frechen M, Horváth E and Gábris G, 1997. Geochronology of Middle to Upper Pleistocene Loess Sections in Hungary. Quaternary Research 48(3): 291-312, DOI 10.1006/qres.1997.1929.

Hayatsu K and Arai F, 1981. Tephrochronological study on the Shinanogawa tephra formations at the middle course of the Sinano River, central Japan. Journal of Geography (Chigaku-zasshi) 91: 88-103 (in Japanese with English abstract).

Huntley DJ and Lamothe M, 2001. Ubiquity of anomalous fading in Kfeldspars and the measurement and correction for it in optical dating. Canadian Journal of Earth Science 38(7): 1093-1106, DOI 10.1139/e01-013.

Kaizuka S, Koike K, Endo K, Yamazaki H and Suzuki T, 2000. Regional Geomorphology of the Japanese Islands. Vol. 4: Geomorphology of Kanto and Izu-Ogasawara. University of Tokyo Press: 349pp. (in Japanese).

Kars RH, Wallinga J and Cohen KM, 2008. A new approach towards anomalous fading correction for feldspar IRSL dating - tests on samples in field saturation. Radiation Measurements 43(2-6): 786790, DOI 10.1016/j.radmeas.2008.01.021.

Lamothe M and Auclair M, 1999. A solution to anomalous fading and age shortfalls in optical dating of feldspar minerals. Earth and Planetary Science Letters 171(3): 319-323, DOI 10.1016/S0012821X(99)00180-6.

Lamothe M, Auclair M, Hamzaoui C and Huot, S, 2003. Towards a prediction of long-term anomalous fading of feldspar IRSL. Radiation Measurements 37(4-5): 493-498, DOI 10.1016/S13504487(03)00016-7.

Machida H and Arai F, 2003. Atlas of Tephra in and around Japan. University of Tokyo Press: 337pp. (in Japanese).

Miyairi Y, Yoshida K, Miyazaki Y, Matsuzaki H and Kaneoka I, 2004. Improved ${ }^{14} \mathrm{C}$ dating of tephra layer (AT tephra, Japan) using AMS on selected organic fractions. Nuclear Instruments and Methods in Physics Research Section B: Beam Interactions with Materials and Atoms 223-224: 555-559, DOI 10.1016/j.nimb.2004.04.103.

Morthekai P, Jain M, Murray AS, Thomsen KJ and Bøtter-Jensen L, 2008. Fading characteristics of martian analogue materials and the applicability of a correction procedure. Radiation Measurements 43(2-6): 672-678, DOI 10.1016/j.radmeas.2008.02.019.

Murray AS and Wintle AG, 2003. The single aliquot regenerative dose protocol: potential for improvements in reliability. Radiation Measurements 37(4-5): 377-381, DOI 10.1016/S13504487(03)00053-2.

Murray AS, Buylaert JP, Thomsen KJ and Jain M, 2009. The Effect of Preheating on the IRSL Signal from Feldspar. Radiation Measurements 44(5-6): 554-559, DOI 10.1016/j.radmeas.2009.02.004.

Novothny Á, Horváth E and Frechen M, 2002. The loess profile of Albertirsa, Hungary - Improvements in loess stratigraphy by luminescence dating. Quaternary International 95-96: 155-163, DOI 10.1016/S1040-6182(02)00036-8

Spooner NA, 1994. The anomalous fading of infrared-stimulated luminescence from feldspars. Radiation Measurements 23(2-3): 625632, DOI 10.1016/1350-4487(94)90111-2. 
Suzuki T, 1995. Origin of so-called volcanic ash soil: thickness distribution in and around central Japan. Bulletin of the Volcanological Society of Japan 40: 167-176 (in Japanese with English abstract).

Suzuki T, 2001. Iizuna-Kamitaru tephra group erupted from the Iizuna volcano of Myoko volcano group in the transition from isotope stage 6 to 5 , and its significance for the chronological study of central Japan. Quaternary Research (Daiyonki-kenkyu) 40: 29-41 (in Japanese with English abstract).

Suzuki T, Fujiwara T and Danhara T, 1998. Fission track ages of eleven Quaternary tephras in north Kanto and south Tohoku regions, central Japan. Quaternary Research (Daiyonki-kenkyu) 37: 95-106 (in Japanese with English abstract).

Thiel C, Buylaert JP, Murray AS, Terhorst B, Hofer I, Tsukamoto S and Frechen M, 2011. Luminescence dating of the Stratzing loess profile (Austria) - Testing the potential of an elevated temperature post-IR IRSL protocol. Quaternary International 234(1-2): 23-31, DOI: 10.1016/j.quaint.2010.05.018.

Thomsen KJ, Bøtter-Jensen L, Denby PM, Moska P and Murray AS,
2006. Developments in luminescence measurement techniques. Radiation Measurements 41(7-8): 768-773, DOI 10.1016/j.radmeas.2006.06.010.

Thomsen KJ, Murray AS, Jain M and Bøtter-Jensen L, 2008. Laboratory fading rates of various luminescence signals from feldspar-rich sediment extracts. Radiation Measurements 43(9-10): 1474-1486, DOI 10.1016/j.radmeas.2008.06.002.

Tsukamoto S, Murray A, Huot S, Watanuki T, Denby PM and BøtterJensen L, 2007. Luminescence property of volcanic quartz and the use of red isothermal TL for dating tephras. Radiation Measurements 42(2): 190-197, DOI 10.1016/j.radmeas.2006.07.008.

Watanuki T, Murray AS and Tsukamoto S, 2005. Quartz and polymineral luminescence dating of Japanese loess over the last 0.6 Ma: Comparison with an independent chronology. Earth and Planetary Science Letters 240(3-4): 774-789, DOI 10.1016/j.eps1.2005.09.027.

Wintle AG, 1973. Anomalous Fading of Thermoluminescence in Minerals. Nature 245(5421): 143-144, DOI 10.1038/245143a0. 